\title{
UJI VALIDITAS UKUR STRES
}

\author{
Dien Dinyati Agustina \\ UIN Syarif Hidayatullah Jakarta \\ dienagustina@gmail,com
}

\begin{abstract}
Stress is a condition of tension that affects emotions, thought processes and one's physical condition. Stress can cause a person to lose interest, appetite to create feelings of inferiority even worse can make someone want to commit suicide. The influence of stress on the body is very large, a person with a high level of stress can affect a person's immune system so that someone becomes susceptible to various diseases. Various types of measuring instruments to measure stress in this case stress in the workplace has been widely used but researchers chose to use a measuring instrument made by the researchers themselves. Therefore this study aims to examine construct validity to detect stress in the workplace. The data used in this study involved I72 female workers in South Jakarta with different occupational backgrounds. The analytical method used is Confirmatory Factor Analysis (CFA) with the help of Listel 8.7 software. The results of the study prove that there are several items in the work stress scale that measure more than one (multidimensional) factor.

Keyword: Test construct validity; work stres; confirmatory factor analysis (CFA)
\end{abstract}

\begin{abstract}
Abstrak
Stres merupakan suatu kondisi ketegangan yang mempengaruhi emosi, proses berpikir dan kondisi fisik seseorang. Stres dapat menyebabkan seseorang kehilangan minat, nafsu makan memunculkan perasaan rendah diri bahkan lebih buruknya dapat membuat seseorang ingin bunuh diri. Pengaruh stres terhadap tubuh sangat besar, seseorang dengan tingkat stres yang tinggi dapat berpengaruh terhadap menurunnya daya tahan tubuh seseorang sehingga membuat seseorang menjadi mudah terserang berbagai macam penyakit. Berbagai macam alat ukur untuk mengukur stres dalam hal ini stres di tempat kerja telah banyak digunakan akan tetapi peneliti memilih menggunakan alat ukur yang dibuat oleh peneliti sendiri. Oleh karena itu penelitian ini bertujuan untuk menguji validitas konstruk untuk mendeteksi stres di tempat kerja. Data yang digunakan dalam penelitian ini melibatkan 172 pekerja wanita di Jakarta Selatan dengan latar belakang pekerjaan yang berbeda. Metode analisis yang digunakan adalah Confirmatory Factor Analysis (CFA) dengan bantuan software Lisrel 8.7. Hasil penelitian membuktikan bahwa terdapat beberapa item dalam skala stres kerja yang mengukur lebih dari satu faktor (multidimensional).
\end{abstract}

Kata kunci : Uji validitas konstruk; stres kerja; confirmatory factor analysis (CFA) 


\section{Pendahuluan}

Stres kerja merupakan hal yang banyak terjadi pada pekerja saat ini. Banyaknya tuntutan pekerjaan dan perubahan teknologi membuat karyawan harus dapat beradaptasi dengan cepat. Akan tetapi, berbagai macam perubahan yang harus dilakukan karyawan tanpa disadari seringkali menimbulkan berbagai macam masalah. Kondisi seperti ini apabila diabaikan oleh individu dan perusahaan dapat menyebabkan timbulnya stres kerja, yang pada akhirnya dapat merugikan perusahaan karena harus menanggung biaya yang dialami karyawannya akibat stres kerja ini. Untuk itu penanganan mengenai adanya stres kerja perlu dilakukan pengukurannya. Saat ini telah banyak alat ukur yang dibuat untuk mengetahui level stres seseorang dalam konteks pekerjaan. Ada beberapa metode atau teknik yang dapat digunakan untuk mengukur stres kerja sebagaimana dilakukan oleh para ahli.

Holmes dan Rahe (dalam Taylor, 2006) membuat suatu alat yang dapat digunakan untuk mengukur stres khususnya yang bersifat psikologis yang disebut sebagai The Social Readjustment Rating Scale (SRRS) dari setiap peristiwa yang membuat seseorang merasa stres (stresfull life events). SRRS ini terdiri dari 43 item yang menggambarkan kejadian dalam hidup. Cara kerja alat ini yaitu dengan mengidentifikasi setiap peristiwa yang paling memaksa individu untuk membuat perubahan dalam hidupnya dan kemudian menetapkan nilai atau poin terhadap peristiwa-peristiwa tersebut untuk mencerminkan jumlah perubahan yang harus dibuat untuk mendapatkan skor stres total dari peristiwa yang terjadi selama setahun. Skor untuk setiap item dalam skala ini menjelaskan catatan kesehatan yang ditunjukan dengan seberapa sering stressor tersebut muncul saat individu itu mengalami sakit tertentu. Sejumlah studi menunjukkan bahwa peristiwa kehidupan yang penuh dengan stres (stressfull life events) rentan memunculkan penyakit. Secara keseluruhan dapat disimpulkan bahwa skala SRRS ini mampu untuk memprediksi penyakit walaupun belum bekerja sangat baik.

Primaldhi (2008) dalam penelitiannya mengenai "Hubungan antara Trait Kepribadian Neuroticism, Strategi Koping, dan Stres Kerja mengukur stres kerja menggunakan Occupational Stress Inventory(Osipow \& Spokane) yang telah diterjemahkan ke dalam bahasa Indonesia oleh Dahlan dan telah diuji reliabilitas dan validitasnya $(\alpha=.7 \mathrm{I})$. Dalam penelitian ini hanya menggunakan Occupational Roles Questionnaire (ORQ) untuk mengukur derajat stres secara keseluruhan yang dialami individu dalam lingkungan kerja. ORQ terdiri dari enam puluh item yang terbagi ke dalam enam skala: Role Overload (8 item), Role Insufficiency (I I item), Role Ambiguity (II item), Role Boundary (I0 item), Work Responsibility (I0 item) dan Physical Environment (I0 item). Hasil analisisnya menunjukkan bahwa range stres kerja yang dialami oleh subjek adalah $\mathrm{I} .25-3.63$, dengan rata-rata $\mathrm{M}=2.686$, dan $\mathrm{SD}$ sebesar $=.44 \mathrm{I}$.

Wijono (2006) dalam penelitiannya yang berjudul "Pengaruh Kepribadian Type A dan Peran terhadap Stres Kerja Manajer Madya” mengukur stres kerja berdasarkan kerangka Spielberger. Alat ukur ini terdiri atas 2 alat ukur yang masing-masing berisi 30 item yang sama. Alat ukur stres kerja bagian A untuk mengukur derajat intensitas atau tinggi rendah stres kerja, dengan alternatif jawaban mempunyai skala I-9. Alat ukur stres kerja B untuk mengidentifikasi tingkat frekuensi dengan alternatif jawaban skala 0-9 bagi individu yang mengalami stres kerja. Validitas dan reliabilitas alat ukur ini diukur berdasarkan Cronbach Alpha dengan angka reliabilitas untuk stres kerja $A=0.8713$ dan stres kerja $B=0.9234$. Hasil penelitian tersebut menunjukkan bahwa terdapat korelasi positif antara kepribadian tipe A dan peran dengan stres kerja manajer madya.

Spielberg (dalam Koslowsky, 200I) mengembangkan alat ukur mengenai stres kerja yang disebut The Spielberger Job Stress Survey (JSS) yang merupakan pengembangan dari alat ukur stres kerja sebelumnya dengan mempergunakan teori Person Environment Fit (P-E Fit). JSS ini terdiri dari 30 item pernyataan, dengan rentang skala 0-9. JSS ini lebih banyak dipakai untuk mengukur tingkat stres dengan tingkat pekerjaan yang lebih tinggi seperti tingkat manajerial, profesional dan klerikal dari berbagai bidang atau lapangan pekerjaan. 
Namun, dalam penelitian ini peneliti memilih untuk membuat sendiri alat ukur stres kerja yang dibuat melalui gejala-gejala stres yang nampak seperti gejala fisik, psikologis, perilaku dan kognitif seperti yang telah dikemukakan oleh Robbins (2003), Koslowsky, Matteson da Ivancevich (dalam Kreitner dan Kinicki, 200I). Gejala ini mirip dengan gejala yang dikemukakan Beehr dan Newman, sehingga melalui gejala-gejala tersebut dapat dilakukan pengukuran dan observasi. Skala stres kerja ini terdiri dari 58 item yang mengukur empat gejala stres

\section{Metode}

Jumlah sampel dalam penelitian ini sebanyak 172 orang pekerja wanita dari berbagai latar belakang pekerjaan. Pengambilan sampel dalam penelitian ini menggunakan teknik non-probability sampling.

Pengumpulan data ini dilakukan untuk penyusunan skripsi peneliti. Dalam penelitian ini validitas konstruk stres kerja diuji dengan analisis faktor konfirmatorik (Confirmatory Factor Analysis /CFA). Adapun yang dimaksud dengan CFA adalah bagian dari analisis faktor yang digunakan untuk menguji sejauh mana masingmasing item valid mengukur apa yang hendak di ukur. Untuk menguji hal ini peneliti menggunakan software Lisrel 8.7 (Jorekog \& Sorbom, 2004). Adapun cara pengujian dengan CFA terdiri dari tiga langkah, yaitu:

I. Menguji apakah hanya satu faktor saja yang menyebabkan item-item saling berkorelasi (hipotesis uni dimensional item). Hipotesis ini diuji dengan chi-square. Untuk memutuskan apakah memang tidak ada perbedaan antara matriks korelasi yang diperoleh dari data dengan matriks korelasi yang dihitung menurut teori. Jika hasil chi-square tidak signifikan $(\mathrm{p}>0.05)$, maka hipotesis nihil yang menyatakan bahwa "tidak ada perbedaan antara matriks korelasi yang diperoleh dari data atau model" tidak ditolak yang artinya item yang diuji mengukur satu faktor saja (uni dimensional). Sedangkan jika nilai chi-square signifikan $(\mathrm{p}<0.05)$ maka hipotesis nihil tersebut ditolak yang artinya item-item yang diuji ternyata mengukur lebih dari satu faktor.

2. Menganalisis item mana yang menjadi sumber tidak fit.

3. Menghitung faktor skor. Jika langkah di atas telah dilakukan, maka diperoleh item-item valid untuk mengukur apa yang ingin diukur (dalam hal ini stres kerja)

\section{Hasil dan Pembahasan}

Pada skala stres kerja terdapat 58 item. Peneliti telah melakukan uji validitas terhadap skala ini dengan menguji apakah 58 item yang ada bersifat unidimensional, artinya hanya mengukur stres kerja. Dari hasil analisis CFA dengan model satu faktor diperoleh model fit dengan Chi-Square $=1300.57, \mathrm{df}=1595, P_{-}$ Value $=1.00000$, RMSEA $=0.000$ seperti gambar I. Karena $P$-Value telah menghasilkan nilai $>0.05$ (signifikan) maka dinyatakan bahwa model dengan satu faktor dapat diterima, bahwa seluruh item mengukur satu faktor saja. Kemudian peneliti melihat apakah item tersebut mengukur faktor yang hendak di ukur secara signifikan dan sekaligus menentukan apakah item tersebut perlu di drop atau tidak. Dalam hal ini yang diuji adalah hipotesis nihil tentang koefisien muatan faktor dari item. Pengujiannya dilakukan dengan melihat nilai t bagi setiap koefisien muatan faktor seperti pada tabel I. 


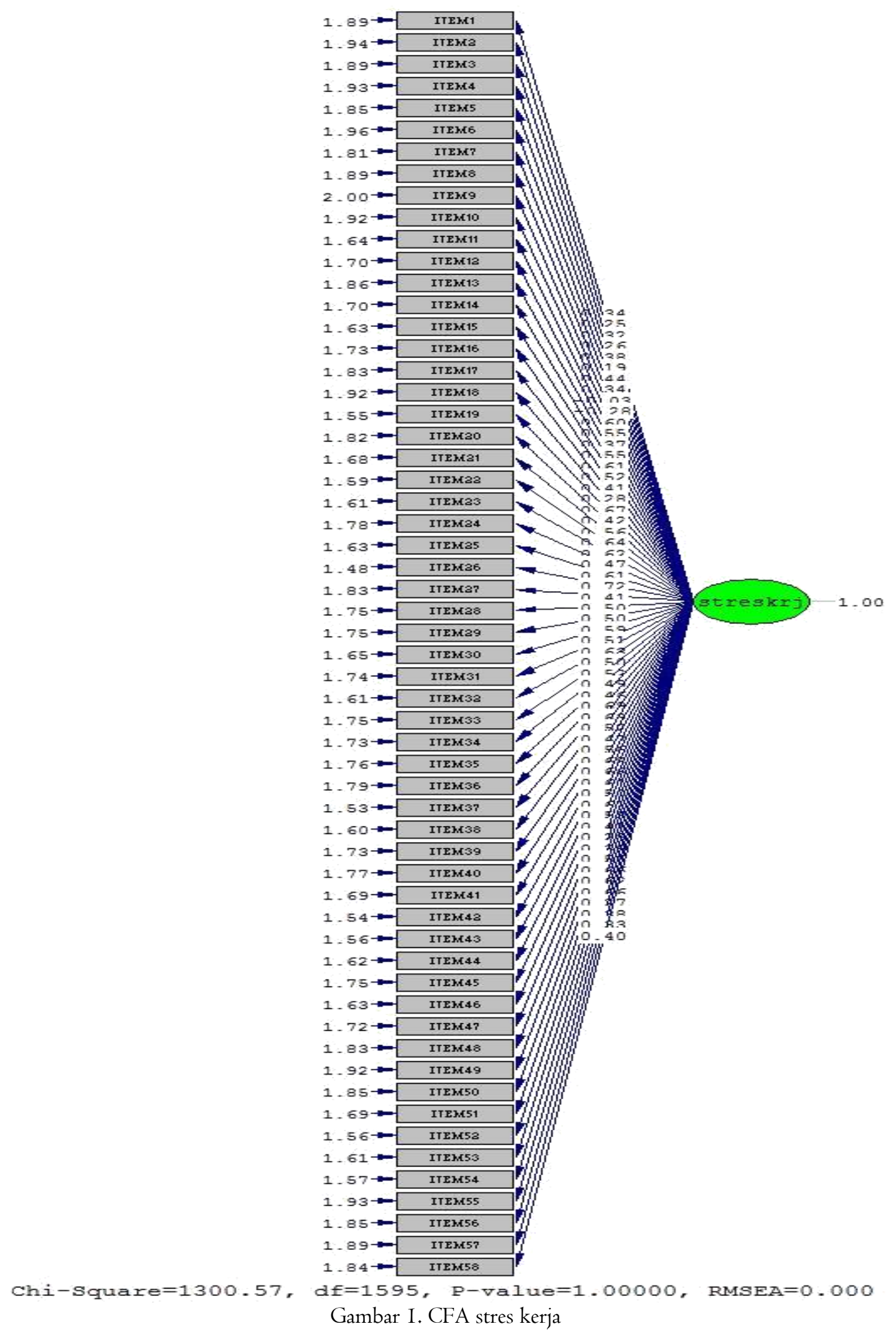


JP3I (Jurnal Pengukuran Psikologi dan Pendidikan Indonesia), 7(2), 2018

Tabel I. Muatan Faktor Item Stres Kerja

\begin{tabular}{|c|c|c|c|c|}
\hline Item & Koefisien & Standar Error & Nilai t & Signifikan \\
\hline 1 & 0.34 & 0.11 & 3.01 & $\sqrt{ }$ \\
\hline 2 & 0.25 & 0.11 & 2.20 & $\sqrt{ }$ \\
\hline 3 & 0.32 & 0.11 & 2.88 & $\sqrt{ }$ \\
\hline 4 & 0.26 & 0.11 & 2.33 & $\sqrt{ }$ \\
\hline 5 & 0.38 & 0.11 & 3.41 & $\sqrt{ }$ \\
\hline 6 & 0.19 & 0.11 & 1.66 & $\mathrm{X}$ \\
\hline 7 & 0.44 & 0.11 & 3.91 & $\sqrt{ }$ \\
\hline 8 & 0.34 & 0.11 & 3.00 & $\sqrt{ }$ \\
\hline 9 & -0.03 & 0.11 & -0.29 & $\mathrm{X}$ \\
\hline 10 & -0.28 & 0.11 & -2.52 & $X$ \\
\hline 11 & 0.60 & 0.11 & 5.57 & $\sqrt{ }$ \\
\hline 12 & 0.55 & 0.11 & 4.98 & $\sqrt{ }$ \\
\hline 13 & 0.37 & 0.11 & 3.33 & $\sqrt{ }$ \\
\hline 14 & 0.55 & 0.11 & 5.02 & $\sqrt{ }$ \\
\hline 15 & 0.61 & 0.11 & 5.64 & $\sqrt{ }$ \\
\hline 16 & 0.52 & 0.11 & 4.75 & $\sqrt{ }$ \\
\hline 17 & 0.41 & 0.11 & 3.67 & $\sqrt{ }$ \\
\hline 18 & 0.28 & 0.11 & 2.49 & $\sqrt{ }$ \\
\hline 19 & 0.67 & 0.11 & 6.25 & $\sqrt{ }$ \\
\hline 20 & 0.42 & 0.11 & 3.77 & $\sqrt{ }$ \\
\hline 21 & 0.56 & 0.11 & 5.17 & $\sqrt{ }$ \\
\hline 22 & 0.64 & 0.11 & 5.92 & $\sqrt{ }$ \\
\hline 23 & 0.62 & 0.11 & 5.78 & $\sqrt{ }$ \\
\hline 24 & 0.47 & 0.11 & 4.22 & $\sqrt{ }$ \\
\hline 25 & 0.61 & 0.11 & 5.60 & $\sqrt{ }$ \\
\hline 26 & 0.72 & 0.11 & 6.83 & $\sqrt{ }$ \\
\hline 27 & 0.41 & 0.11 & 3.66 & $\sqrt{ }$ \\
\hline 28 & 0.50 & 0.11 & 4.52 & $\sqrt{ }$ \\
\hline 29 & 0.50 & 0.11 & 4.56 & $\sqrt{ }$ \\
\hline 30 & 0.59 & 0.11 & 4.63 & $\sqrt{ }$ \\
\hline 31 & 0.51 & 0.11 & 4.63 & $\sqrt{ }$ \\
\hline 32 & 0.63 & 0.11 & 5.82 & $\sqrt{ }$ \\
\hline 33 & 0.50 & 0.11 & 4.50 & $\sqrt{ }$ \\
\hline 34 & 0.52 & 0.11 & 4.70 & $\sqrt{ }$ \\
\hline 35 & 0.49 & 0.11 & 4.40 & $\sqrt{ }$ \\
\hline 36 & 0.46 & 0.11 & 4.14 & $\sqrt{ }$ \\
\hline 37 & 0.69 & 0.11 & 6.43 & $\sqrt{ }$ \\
\hline 38 & 0.63 & 0.11 & 5.84 & $\sqrt{ }$ \\
\hline 39 & 0.52 & 0.11 & 4.72 & $\sqrt{ }$ \\
\hline 40 & 0.47 & 0.11 & 4.29 & $\sqrt{ }$ \\
\hline 41 & 0.56 & 0.11 & 5.12 & $\sqrt{ }$ \\
\hline 42 & 0.48 & 0.11 & 6.35 & $\sqrt{ }$ \\
\hline 43 & 0.66 & 0.11 & 6.20 & $\sqrt{ }$ \\
\hline 44 & 0.61 & 0.11 & 5.68 & $\sqrt{ }$ \\
\hline 45 & 0.50 & 0.11 & 4.49 & $\sqrt{ }$ \\
\hline 46 & 0.61 & 0.11 & 5.59 & $\sqrt{ }$ \\
\hline 47 & 0.53 & 0.11 & 4.84 & $\sqrt{ }$ \\
\hline
\end{tabular}




\begin{tabular}{|c|c|c|c|c|}
\hline 48 & 0.41 & 0.11 & 3.70 & $\sqrt{ }$ \\
\hline 49 & 0.29 & 0.11 & 2.55 & $\sqrt{ }$ \\
\hline 50 & 0.39 & 0.11 & 3.49 & $\sqrt{ }$ \\
\hline 51 & 0.56 & 0.11 & 5.13 & $\sqrt{ }$ \\
\hline 52 & 0.66 & 0.11 & 6.20 & $\sqrt{ }$ \\
\hline 53 & 0.62 & 0.11 & 5.74 & $\sqrt{ }$ \\
\hline 54 & 0.66 & 0.11 & 6.12 & $\sqrt{ }$ \\
\hline 55 & 0.27 & 0.11 & 2.41 & $\sqrt{ }$ \\
\hline 56 & 0.38 & 0.11 & 3.43 & $\sqrt{ }$ \\
\hline 57 & 0.33 & 0.11 & 2.96 & $\sqrt{ }$ \\
\hline 58 & 0.40 & 0.11 & 3.60 & $\sqrt{ }$ \\
\hline
\end{tabular}

Keterangan: tanda $\sqrt{ }=$ signifikan $(\mathrm{t}>\mathrm{I} .96) ; \mathrm{X}=$ tidak signifikan

Pada tabel I dapat terlihat bahwa terdapat tiga item yang tidak signifikan yaitu faktor item 6 tidak signifikan karena $t$-value $<$ I.96, kemudian pada $t$-value koefisien muatan faktor item 9 dan I0 tidak signifikan dan memiliki koefisien negatif.

Pada model pengukuran ini terdapat kesalahan pengukuran item yang saling berkorelasi, artinya item-item tersebut bersifat multidimensional dan tidak hanya mengukur apa yang seharusnya diukur. Berdasarkan adanya korelasi kesalahan pengukuran seluruh item, maka ada tiga item yang digugurkan yaitu item 6, 9 dan IO.

\section{Penutup}

Untuk penelitian lebih lanjut peneliti memiliki beberapa saran dalam penelitian ini anatara lain, memperbanyak jumlah sampel dan membuatnya lebih variatif dan menggunakan alat ukur stres kerja yang baku dan telah banyak digunakan antar budaya untuk menghindari terjadinya.

\section{Daftar Pustaka}

Kreitner, Robert \& Kinicki, A. 200I. Organizational behavior $5^{\text {th }}$ Ed. New York: Mc Graw Hill, Inc.

Koslowsky, Meni. 200I. Modeling the stress-strain relationship in work settings.

New York: Routledge.

Primaldhi, Alfindra. 2008. Hubungan antara trait kepribadian neuroticism, strategi koping, dan stres kerja. Jurnal Psikologi Sosial vol.I4 no. 03.

Robbins, Stephen P. 2003. Perilaku organisasi. Jakarta: PT. Indeks Kelompok Gramedia.

Taylor, Shelley E. 2006. Health psychology sixth edition. New York: Mc Graw Hill International Edition.

Wijono, Sutarto. 2006. Pengaruh kepribadian type A dan peran terhadap stres kerja manajer madya. Insan vol.8 no.3. 